\title{
Reuse of Newspaper As An Adsorbent For Cu (II) Removal By Citric Acid Modification
}

\author{
Mardiah, Rif'an Fathoni, Pratiwi Pudyaningtyas, Hamdania Gamu, Rinaldy \\ Department of Chemical Engineering, Faculty of Engineering, Mulawarman University, Indonesia
}

\begin{abstract}
High Consumption of paper, bring the impact of the waste paper itself. And the utilization of the paper is limited to recycled products and crafts, whereas paper such as newspaper still contains cellulose that can be potential to be used as a heavy metal adsorbent. In this study, newspaper was dissolved in sodium bicarbonate to reduce various impurities and then was reacted with citric acid (CA). The modified adsorbent was characterized by FTIR and was tested for adsorb $\mathrm{Cu}(\mathrm{II})$ in artificial solution. After adsorption process, the solution was filtered and analysed using Atomic Absorption Spectrophotometer (AAS). The adsorption experimental data was fitted to Langmuir, Freundlich, Tempkin, and Dubinin-Radushkevich for equilibrium model and was fitted to pseudo first order reaction and pseudo second order reaction for kinetic studies. The result showed that CA-modification newspaper able to remove heavy metals $\mathrm{Cu}(\mathrm{II})$ in solution.
\end{abstract}

\section{Introduction}

The growth of pulp and paper industry is still increasing. Over 400 million metric ton paper and cardboard are produced worldwide every year and consumtion of paper reached $400 \%$ in the last 40 years [1]. From newspaper to paper wrap, paper is still everywhere and mostly ends up in landfills so it will produce accumulated paper waste.

Meanwhile, the utilization of the paper is limited to recycled products and crafts, whereas paper such as newspaper still contains cellulose that can be used as a heavy metal adsorbent. Exposure to heavy metals can cause cancer in humans. For example Copper $(\mathrm{Cu})$, if humans consumed continuously will cause irritation, itching, skin diseases, cancer, liver, kidneys and lungs [2].

Activated carbon as adsorbent has been widely used. However, activated carbon is an expensive material and activated carbon is widely used for adsorption of organic components instead of heavy metals [3].

Old newspapers is one source of cellulose and has the potential to be used as a heavy metal adsorbent. As research conducted by Chakravarty et al [4] used the newspaper that has been modified as adsorbent, capable of reducing the metal content of $\mathrm{Zn} 9.20 \mathrm{mg} / \mathrm{g}$ with initial concentration of Zinc $10.31 \mathrm{mg} / \mathrm{lt}$. Then Chakravarty et al [2] conducted a study with an adsorbent newspaper to absorb $\mathrm{Cu}$ (II), obtained a maximum loading capacity of $30 \mathrm{mg} / \mathrm{g}$ with initial

\footnotetext{
Corresponding author: mardiah@ft.unmul.ac.id
}

concentration of $\mathrm{Cu}$ (II) $20 \mathrm{mg} / 1$. Dehghani et al [5] using old newspapers that have been modified to absorb chromium of $59.88 \mathrm{mg} / \mathrm{g}(64 \%)$ with a dose of adsorbent $3 \mathrm{~g} / 1$ and a contact time of 60 minutes. Marshall [6] enhanced the adsorption capacity of soybean hulls for copper uptake by employing base treatment before modification with citric acid (CA). Pitsari et. al [7] showed that Citric Acid- modified newspaper pulp is an effective adsorbent for the removal of $\mathrm{Pb}^{2+}$ from wastewater. Lignocellulosic materials exhibit high metal removal ability that is attributed to the sorption properties of cellulose and its affinity towards metal ions. Metals interact with the negatively charged functional groups of cellulose such as carbonyls, carboxyl groups, hydroxyls, phenolics and sulfonic acids [7]. Therefore newspaper needs to be modified. One of treatment for modified is by using citric acid to form esterification [3].

\section{Materials and Methods}

This research was conducted in two stage: the first was preparation adsorbent from old newspapers. Newspaper was reduced in size, then was dissolved in a solution of $10 \%$ of sodium bicarbonate. Then the adsorbent filtered and washed with distilled water until $\mathrm{pH}$ 6.5-7. Then it was dried in the oven. After that, it was reacted with $0.5 \mathrm{M}$ citric acid for 90 minutes then filtered and washed with $200 \mathrm{ml}$ of distilled water. The adsorbent was dried in the oven until the weight is constant. The adsorbent was characterized by Fourier 
Transform InfraRed (FTIR). The second stage, the parameters were tested initial concentration of $\mathrm{Cu}$ (II), adsorbent doses, and contacted time.

After the adsorption process was complete, the solution was filtered. Both initial and final concentration of $\mathrm{CuSO}_{4} .5 \mathrm{H}_{2} \mathrm{O}$ was analyzed using atomic absorption spectrophotometer.

Percent of $\mathrm{Cu}$ (II) removal and adsorption capacity, was calculated using the following equation:

$$
\% \text { removal }=\frac{C_{i-} C_{e}}{C_{i}} \times 100
$$

Adsorption capacity:

$$
q_{e}=\frac{c_{i-} c_{e}}{m} \times V
$$

Information :

$\mathrm{Ci}$ : initial concentration of $\mathrm{Cu}(\mathrm{II})(\mathrm{mg} / \mathrm{l})$

Ce: the final concentration of $\mathrm{Cu}$ (II) $(\mathrm{mg} / \mathrm{l})$

qe: $\mathrm{Cu}$ (II) which adsorbed by the adsorbent ( $\mathrm{mg} / \mathrm{g}$ )

$\mathrm{V}$ : total volume of solution (liters)

$\mathrm{m}$ : dose of adsorbent ( $\mathrm{g})$

\section{Isotherm adsorption Model}

Adsorption Model approach which used in this study was the Langmuir, Freundlich, Tempkin, and Dubinin-Radushkevich adsorption. The Langmuir equation model in the form of concentration as follows:

$$
q=\frac{Q b C}{1+b c}
$$

Where $\mathrm{q}$ is the adsorbate adsorbed mass per unit mass of adsorbent ( $\mathrm{mg} / \mathrm{g}$ ), Q is an adsorption capacity $(\mathrm{mg} / \mathrm{g}), \mathrm{C}$ is the concentration of adsorbate in solution and $b$ is the equilibrium constant. The model of the Langmuir adsorption can be expressed in linear form:

$$
\frac{C}{q}=\frac{1}{Q b}+\frac{C}{Q}
$$

Where $\mathrm{Q}$ and $\mathrm{B}$ are constants, and obtained from plotting a graph $\mathrm{C} / \mathrm{q}$ vs. C. This equation is a straight line with a slope and intercept $\mathrm{Q}$ and $\mathrm{Q}, \mathrm{b}$.

The well-known Freundlich equation can be written as

$$
\log q e=\log K_{f}+\frac{1}{n} \log C e
$$

where $n$ and $k$ are the Freundlich constant.

The Temkin isotherm has a convenient linear form, which is expressed by the following equation:

$$
\begin{aligned}
\mathrm{qe} & =\mathrm{B} \ln \mathrm{A}_{\mathrm{T}}+\mathrm{B} \ln \mathrm{Ce} \\
\mathrm{B} & =\mathrm{RT} / \mathrm{b}
\end{aligned}
$$

where, $A_{T}$ is Temkin isotherm equilibrium binding constant corresponding to the maximum binding energy $(\mathrm{L} / \mathrm{g}), \mathrm{B}$ is constantly related to the heat of sorption $(\mathrm{J} / \mathrm{mol}), \mathrm{R}$ is the universal gas constant $(8.314 \mathrm{~J} / \mathrm{mol} / \mathrm{K})$, $\mathrm{T}$ is absolute temperature at $298 \mathrm{~K}^{\circ}, \mathrm{b}$ is Temkin isotherm constant,which indicates the adsorption potential of the adsorbent. Both $\mathrm{A}_{\mathrm{T}}$ and $\mathrm{B}$ can be determined from a plot qe vs. $\ln \mathrm{Ce}$.

Dubinin-Radushkevich (D-R) isotherm :

$$
\ln \mathrm{qe}=\ln \mathrm{Q}_{\mathrm{m}}-\mathrm{k}_{\mathrm{d}} \varepsilon^{2}
$$

where $\varepsilon$ (Polyani potential) is $[R T \ln (1+1 / C \mathrm{e})], Q \mathrm{~m}$ the theoretical saturation capacity $(\mathrm{mg} \mathrm{g}-1), k \mathrm{~d}$ a constant related to adsorption energy $\left(\mathrm{mol}^{2} \mathrm{KJ}^{-2}\right), R$ is the gas constant $\left(\mathrm{kJ} \mathrm{mol}^{-1} \mathrm{~K}^{-1}\right)$ and $T$ is the temperature $(\mathrm{K})$. The slope of the plot $\ln q$ e versus $\varepsilon^{2}$ gives the $K_{\mathrm{d}}$ and $Q_{\mathrm{m}}$ values

\section{Adsorption kinetics}

The linear form of Lagergren's pseudo-first-order model is generally expressed as follows:

$$
\log \left(q_{e}-q_{t}\right)=\log q_{e}-\frac{k_{1} t}{2.303}
$$

$\mathrm{q}_{\mathrm{t}}$ is the amount of $\mathrm{Cu}$ (II) adsorbed at time $\mathrm{t}(\mathrm{min}), \mathrm{k}_{1}$ is the pseudo first-order rate constant for the kinetic model (1/min).

Ho and McKay in Deghani et.al [5] described pseudosecond-order model as the kinetic process of the adsorption. The equations can be rearranged to obtain linearized as follows :

$$
\frac{t}{q_{t}}=\frac{1}{k_{2} q_{e}^{2}}+\frac{t}{q_{e}}
$$

where, $\mathrm{k}_{2}$ is the rate constant of pseudo-second-order kinetics $(\mathrm{g} / \mathrm{mg} \cdot \mathrm{min})$.

\section{Result and Discussion}

\subsection{Characterization of adsorbent}

The surface functional groups were analysed by Fourier transform infrared spectroscopy (FTIR) in the Treated Newspaper (TN) as describe at Figure 1.

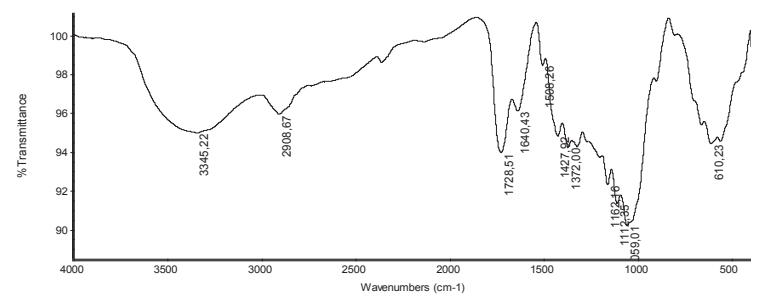

Fig. 1. FTIR spectra of citric-acid modification Newspaper

The FTIR spectra of CA- modified newspaper was in the region 4000- $500 \mathrm{~cm}^{-1}$, showing characteristic cellulose peaks in the range of $1000-1200 \mathrm{~cm}^{-1}$. The band near $1000-1100 \mathrm{~cm}^{-1}$ corresponds to C- O- C 
groups from $\beta$ - (1- 4)- glycosidic bonds in Cellulose. The peaks at $1372 \mathrm{~cm}^{-1}$ are assigned to $\mathrm{O}-\mathrm{H}$ bending and $\mathrm{CH}_{2}-$ wagging vibrations. The band near $3500 \mathrm{~cm}^{-1}$ is assigned to hydroxyl vibrations. The wave numbers at $2908 \mathrm{~cm}^{-1}$ are characteristic of alkaline groups and the band near $1640 \mathrm{~cm}^{-1}$ correspond to bending vibrations of fibres due to the absorbed water. The introduction of additional carboxyl groups to newspaper pulp using CA was further confirmed by characteristic vibration at 1728 $\mathrm{cm}^{-1}$ originating from the $\mathrm{C}=\mathrm{O}$ stretch of ester carbonyl group and carboxylate ions which was the result of CA esterification [7].

\subsection{Effect of adsorbent dose}

Fig. 2 shows the adsorption of $\mathrm{Cu}$ (II) with varying weight of the adsorbent. It indicates that the uptake of $\mathrm{Cu}(\mathrm{II})$ increases as the adsorbent dose increases from $0.05,0.1,0,25,0,5$ to $1 \mathrm{~g}$ which entered into a $50 \mathrm{ml}$ $\mathrm{CuSO}_{4} \cdot 5 \mathrm{H}_{2} \mathrm{O}$ with a concentration was $100 \mathrm{mg} / 1$ for 60 minutes therefore $\mathrm{Cu}$ (II) in solution was decreased.

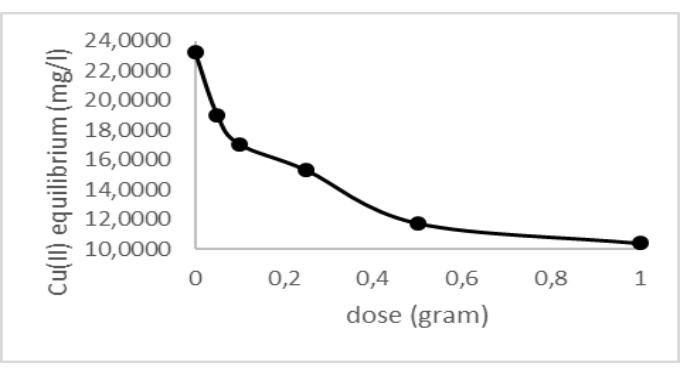

Fig.2. Effect of adsorbent dose

The adsorbent dose of $1 \mathrm{~g}$ was able to adsorb $55,30 \% \mathrm{Cu}$ (II) from $50 \mathrm{~mL}$ of $23,27 \mathrm{mgL}^{-1} \mathrm{Cu}$ (II) in solution. This increase of $\mathrm{Cu}(\mathrm{II})$ removal may be attributed to the active site of the adsorbent surface (Fig.3).

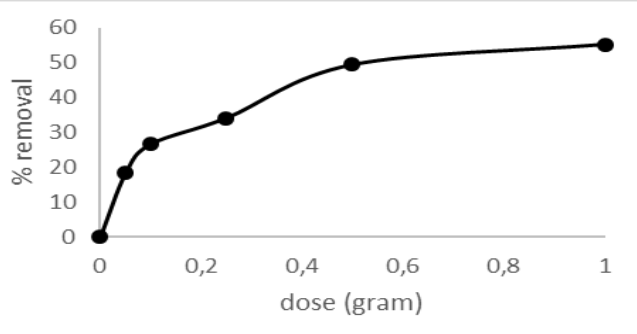

Fig. 3. Removal of $\mathrm{Cu}(\mathrm{II})$ as an effect of adsorbent dose

\subsection{Effect of initial concentration}

The experiments were done with variable initial copper concentration $(4.2,23.27,35.40$, and 42.42 $\mathrm{mg} / \mathrm{L})$, with adsorbent dose $(1 \mathrm{~g} / 50 \mathrm{~mL})$, contact time (1 h) at room temperature. The percentage of $\mathrm{Cu}$ (II) ion uptake on the adsorbent is presented in Fig.4. Fig. 4 shows that by increasing initial $\mathrm{Cu}$ (II) concentration, copper removal efficiency is decreased but increased in adsorption capacity (Fig. 5). Thus, results suggest that adsorption capacity and removal efficiency of adsorbent is dependent on the initial concentration of copper [5].

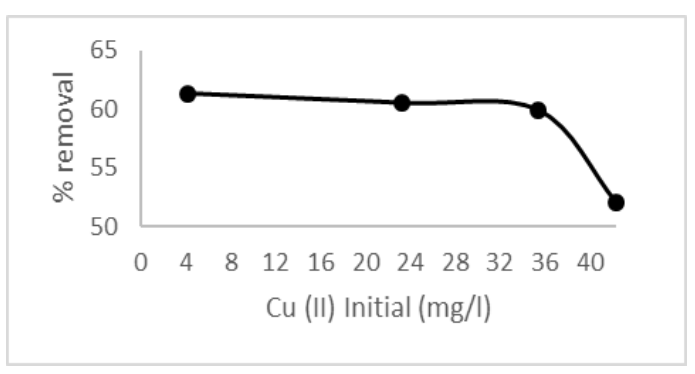

Fig. 4. Removal of $\mathrm{Cu}$ (II) as an effect of $\mathrm{Cu}$ (II) initial

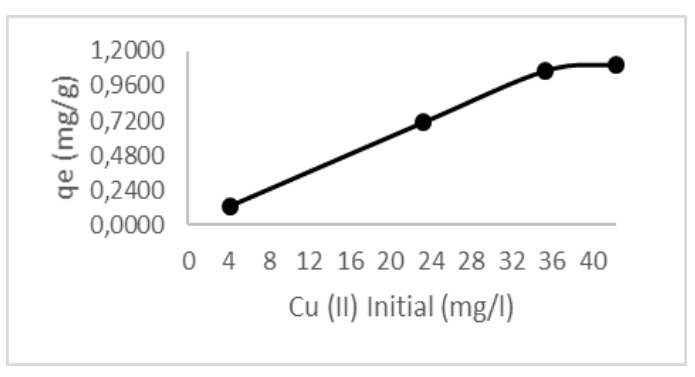

Fig. 5. Adsorption capacity of $\mathrm{Cu}(\mathrm{II})$ as an effect of $\mathrm{Cu}$ (II) initial

\subsection{Effect of contact time}

The effect of contact time $(15,30,60,90$, and 120 minutes) was studied for an initial $\mathrm{Cu}$ (II) concentration of 23, $27 \mathrm{mg} / \mathrm{L}$; Adsorbent dose of $1 \mathrm{~g} / 50 \mathrm{~mL}$ at room temperature. Fig. 6 shows that $\mathrm{Cu}$ (II) in solution was decreased with contact time. The maximum efficiency for removal $\mathrm{Cu}(\mathrm{II})$ adsorption was $66,78 \%$ at $120 \mathrm{~min}$ (Fig. 7).

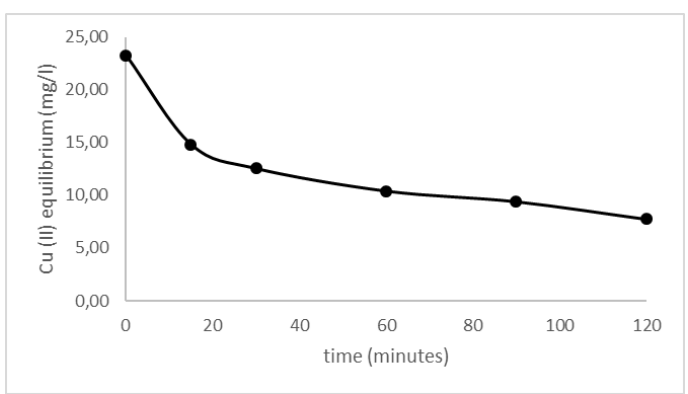

Fig. 6. Effect of contact time 


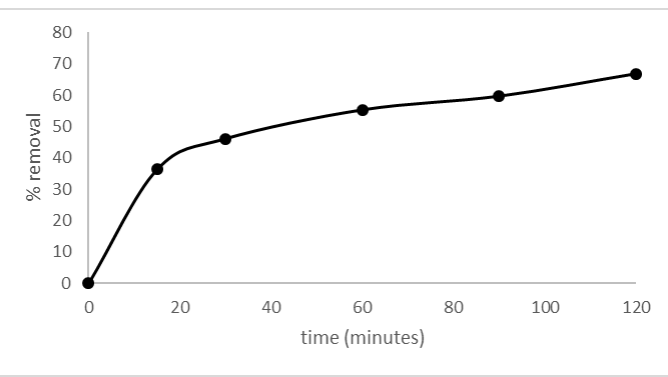

Fig. 7. Removal of $\mathrm{Cu}(\mathrm{II})$ as an effect of contact time

\subsection{Adsorption Isotherms}

The equilibrium adsorption of $\mathrm{Cu}$ (II) on the $\mathrm{CA}$ modified newspaper was fitted using adsorption isotherms as discussed before. Fig. 8-11 shows Langmuir, Freundlich, Tempkin, and DubininRadushkevich adsorption.

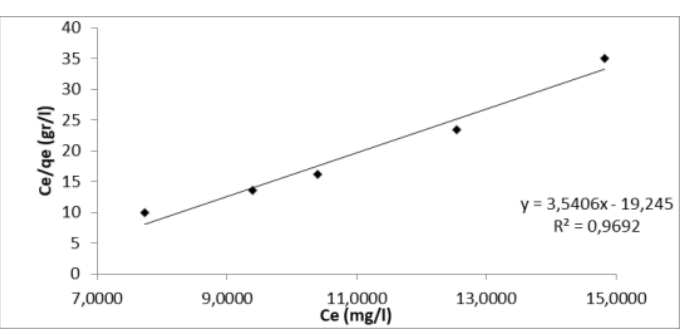

Fig. 8. Langmuir isotherm

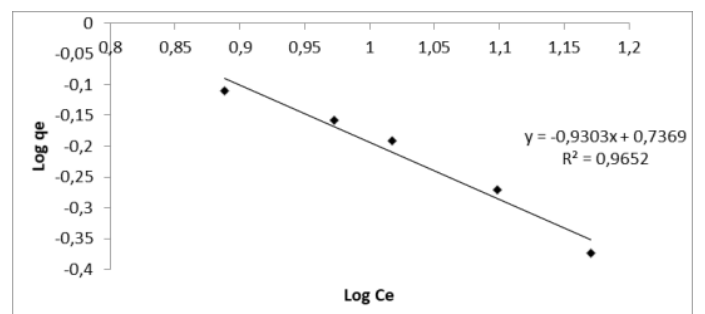

Fig. 9. Freundlich isotherm

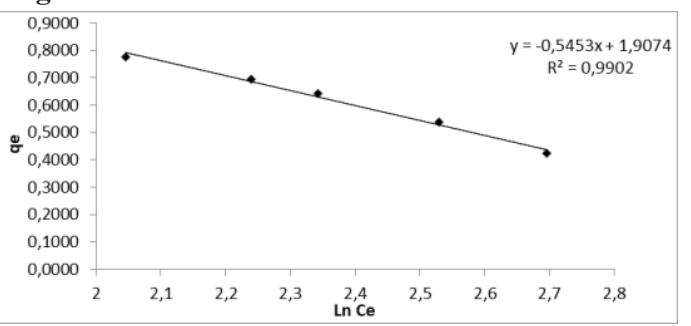

Fig. 10. Tempkin isotherm

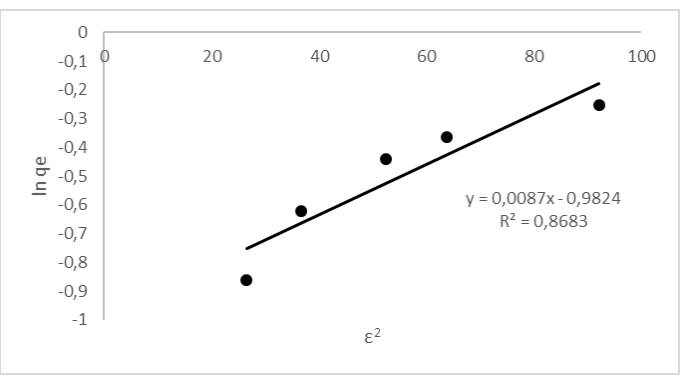

Fig. 11. Dubinin-Radushkevich (D-R) isotherm
Constants values of all four isotherms are presented in Table 1.

Table 1. Isotherm parameters and $\mathrm{R}^{2}$ values for adsorption of $\mathrm{Cu}$ (II) onto CA- modified newspaper

\begin{tabular}{clc}
\hline Isotherm & \multicolumn{1}{c}{ Constants } & Value \\
\hline Langmuir & $\mathrm{b}\left(\mathrm{L} \mathrm{mg}^{-1}\right)$ & 0.1840 \\
& $\mathrm{Q}_{\mathrm{m}}\left(\mathrm{mg} \mathrm{g}^{-1}\right)$ & 0.2824 \\
Freundlich & $\mathrm{R}^{2}$ & 0.9692 \\
& $\mathrm{n}$ & -1.075 \\
& $\mathrm{k}_{\mathrm{f}}$ & 5.4563 \\
Tempkin & $\mathrm{R}^{2}$ & 0.9652 \\
& $\mathrm{~A}_{\mathrm{T}}\left(\mathrm{L} \mathrm{g}^{-1}\right)$ & 0.0298 \\
& $\mathrm{~B}\left(\mathrm{~J} \mathrm{~mol}^{-1}\right)$ & -0.5453 \\
& $\mathrm{R}^{2}$ & 0.9902 \\
Dubinin-Radushkevich & $\mathrm{K}_{\mathrm{d}}\left(\mathrm{mol}^{2} / \mathrm{KJ}^{2}\right)$ & -0.0087 \\
& $\mathrm{Q}_{\mathrm{m}}\left(\mathrm{mg} \mathrm{g}^{-1}\right)$ & 0.3744 \\
& $\mathrm{R}^{2}$ & 0.8683 \\
\hline
\end{tabular}

The results showed that Tempkin gave the best fit for the $\mathrm{Cu}(\mathrm{II})$ adsorption by CA-modified newspaper with $\mathrm{R}^{2}=$ 0.99 .

\subsection{Adsorption Kinetics}

The linear form of Lagergren's pseudo-first-order model shows in Fig.12. and Pseudo- second order shows in Fig.13. at adsorbent dose 1 gram in $50 \mathrm{ml}$ of 23,27 $\mathrm{mg} / \mathrm{l} \mathrm{Cu}$ (II) solution.

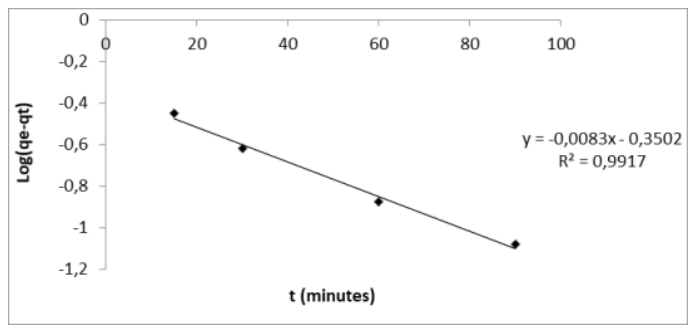

Fig. 12. Pseudo-first-order kinetics plots for adsorption of $\mathrm{Cu}$ (II) onto CA-modified newspaper

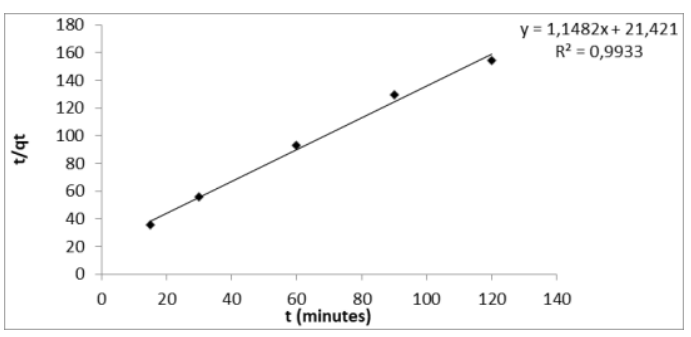

Fig. 13. Pseudo-second-order kinetics plots for adsorption of $\mathrm{Cu}$ (II) onto CA-modified newspaper

Kinetic parameters for the removal of $\mathrm{Cu}$ (II) by CAmodified newspaper are shows in Table 2. 
Table 2. Kinetic parameter for the removal of $\mathrm{Cu}$ (II) by CAmodified newspaper

\begin{tabular}{|c|c|c|c|}
\hline \multirow{2}{*}{ Pseudo 1st order model } & $\mathrm{k}_{1}$ & $\begin{array}{c}\mathrm{q}_{\mathrm{e}} \\
\left(\mathrm{mg} \mathrm{g}^{-1}\right)\end{array}$ & $\mathrm{R}^{2}$ \\
\hline & 0.8065 & 0.4465 & 0.9917 \\
\hline \multirow[t]{2}{*}{ Pseudo 2nd order model } & $\mathrm{k}_{2}$ & $\begin{array}{c}\mathrm{q}_{\mathrm{e}} \\
\left(\mathrm{mg} \mathrm{g}^{-1}\right)\end{array}$ & $\mathrm{R}^{2}$ \\
\hline & 0.0354 & 11.482 & 0.9933 \\
\hline
\end{tabular}

A comparison of Figs. 12 and 13 showed that pseudo-second-order was the best model for the Copper (II) removal onto CA-modified newspaper with a higher correlation coefficient $\left(\mathrm{R}^{2}=0.9933\right)$ than for pseudofirst-order $\left(\mathrm{R}^{2}=0.9917\right)$.

\section{Conclussion}

The initial concentration of the solution, adsorbent dose and contacted time has been tested in this study. Adsorbent from newspapers which modified citric acid can be used to reduce the levels of $\mathrm{Cu}$ (II) in the solution.

We acknowledged the LP2M Mulawarman University, Ministry of Research, Technology and Higher Education for funding the research.

\section{References}

1. Pratima Bajpai, Pulp and Paper Industry, Elsevier (2015)

2. S.Chakravarty, S. Pimple, Hema T. Chaturvedi, S. Singh, K.K. Gupta. Journal of Hazardous Materials, 159, 396-403 (2008)

3. David William O'Connell, Colin Birkinshaw, O'Dwyer Thomas Francis. Bioresource Technology,99, 6709-6724, (2008)

4. S.Chakravarty, S. Bhattacharjee, K.K. Gupta,M. Singh, H.T. Chaturvedi, S. Maity. Bioresour. Technol,98 , 3136-3141, (2007)

5. Mohammad Hadi Dehghani, Daryoush Sanaei, Imran Ali , Amit Bhatnagar. Journal of Molecular Liquids, 215, 671-679, (2016)

6. W.E. Marshall, L.H.Wartelle, D.E. Boler, C.A. Toles. Environ. Technol, 21, 601-607,(2000)

7. S. Pitsari, E. Tsoufakis, M. Loizidou. Chemical Engineering Journal, 223, 18-30, 2013. 